\title{
Desenvolvimento e acumulação por espoliação: o caso do território Cantuquiriguaçu - Paraná
}

Unequal development and accumulation by spolation: the case of Cantuquiriguaçu - Paraná

Ivo Marcos Theis - Professor do Departamento de Economia da FURB. Economista, Dr. em Geografia pela University of Tübingen, TUEBINGEN, Alemanha. Professor do Programa de Pós-Graduação (mestrado e doutorado) em Desenvolvimento Regional FURB. E-mail: theis@furb.br

Luis Claudio Krajevski - Universidade Federal da Fronteira Sul. Prof. de Teoria Econômica - Campus Laranjeiras do Sul. Afastado para realização de doutorado. E-mail: luisclaudio@, uffs.edu.br

\section{Resumo}

O Território Cantuquiriguaçu é a segunda microrregião menos desenvolvida do Estado do Paraná. Dentre as justificativas para esta situação, este ensaio discorre sobre a ideia de que a acumulação por espoliação contribui para o atraso desta região se comparada as demais microrregiões paranaenses. Desta forma, o objetivo deste artigo é verificar até que ponto a acumulação por espoliação promove o desenvolvimento desigual das regiões, especialmente quanto ao desenvolvimento do Território Cantuquiriguaçu. Para isso, se utiliza de revisão bibliográfica e documental a respeito das ações adotadas, bem como de dados socioeconômicos do Paraná. A análise consiste na comparação destes dados entre o Território Cantuquiriguaçu com os dados estaduais. Os resultados não só confirmam o atraso da região, como também indicam que o intenso processo de concessões e privatizações, ocorrido a partir do final dos anos 1990, promoveu práticas de acumulação por espoliação via ação estatal, impulsionando as disparidades regionais anteriormente existentes.

\section{Palavras-chave}

Desenvolvimento desigual, acumulação por espoliação, Território Cantuquiriguaçu, desenvolvimento regional.

\begin{abstract}
The Territory of Cantuquiriguaçu is the second least developed micro region in the State of Paraná - Brazil. Among the justifications for this situation, this essay discusses the idea that accumulation by spoliation contributes to the delay of this region when compared to the other micro regions of Paraná. In this way, the objective of this article is to verify to what extent the accumulation by spoliation promotes the unequal development of the regions, especially regarding the development of the Cantuquiriguaçu Territory. For this, it is used a bibliographical and documentary revision regarding the adopted actions, as well as socioeconomic data of Paraná. The analysis consists of comparing these data to the Cantuquiriguaçu Territory and the state data. The results not only confirm the region's backwardness, but also indicate that the intense process of concessions and privatizations, which took place in the late 1990s, promoted practices of accumulation through spoliation through state action, boosting previously existing regional disparities.
\end{abstract}

\section{Keywords}

Unequal development, accumulation by spoliation, Territory Cantuquiriguaçu, regional development. 


\section{INTRODUÇÃO}

As discussões sobre desenvolvimento regional têm conquistado cada vez mais espaço na academia nos últimos anos. Objeto de estudo de diferentes campos de conhecimento, como economia, ciências sociais, ciência política e geografia, a bibliografia sobre o tema já é vasta e diversificada. No entanto, não há consenso sobre quais motivos determinam que uma região é mais ou menos desenvolvida, apesar de diversas contribuições teóricas e empíricas. Algumas vertentes teóricas envolvem a localização, outras consideram o papel do Estado, até as recentes abordagens que atrelam o desenvolvimento local a variáveis endógenas. Portanto, investigar os motivos que determinam o sucesso ou não de uma região, considerando aspectos socioeconômicos, padece de uma definição de critérios a respeito de qual abordagem deve ser utilizada. Neste sentido se procurará verificar como o Estado, através da promoção de políticas públicas, contribuiu para a promoção do desenvolvimento regional.

O Território Cantuquiriguaçu é considerado a segunda região menos desenvolvida socioeconomicamente do Paraná. Este "atraso" é constatado através de indicadores econômicos (como renda e produção), representação política, conflitos socioambientais, entre outros. Em contrapartida, outras microrregiões apresentam melhores resultados, mesmo que exibam desigualdades internas. Diante deste cenário, cabe questionar: até que ponto as políticas governamentais que têm sido adotadas promovem o desenvolvimento de uma região? Como determinada região torna-se mais ou menos desenvolvida, considerando a política pública implementada? Neste artigo, parte-se do desenvolvimento restringido do Território Cantuquiriguaçu e o relaciona com a hipótese da acumulação por espoliação (HARVEY, 2004, p. 121).

Alguns estudos têm sido elaborados nos últimos anos a respeito do Território Cantuquiriguaçu, com destaque para o "Diagnóstico Socioeconômico do Território Cantuquiriguaçu” (2004), fruto do acordo de Cooperação Técnica entre o Governo do Paraná e a FAO (Organização das Nações Unidas para a Agricultura e Alimentação) e os Cadernos Municipais do Instituto Paranaense de Desenvolvimento Econômico e Social - IPARDES. Contudo, há a necessidade de examinar melhor as ações do Estado paranaense e suas consequências sobre o território e seu desenvolvimento. O objetivo deste estudo é, precisamente, contribuir para a compreensão do desenvolvimento desigual entre as

Elaborado pela Empresa Paranaense de Assistência Técnica e Extensão Rural (EMATER) em conjunto com o Instituto Agrônomo do Paraná (IAPAR), Secretaria de Estado de Agricultura e Abastecimento (SEAB), Secretaria de Estado de Planejamento e Coordenação Geral, IPARDES e Conselho de Desenvolvimento do Território Cantuquiriguaçu (CONDETEC).

Novos Cadernos NAEA • v. 20 n. $2 \cdot$ p. 9-26 • maio-ago 2017 
microrregiões do Paraná considerando, especialmente, a atuação do Estado, com ênfase para o caso do Território Cantuquiriguaçu. Mais especificamente, o propósito é identificar se, diante da desigualdade regional paranaense, o Estado intervém de forma a favorecer o processo de acumulação por espoliação, o que acarretaria no aprofundamento das desigualdades.

Assim, este artigo consiste de uma análise bibliográfica e documental de dados socioeconômicos do Território Cantuquiriguaçu (e do Paraná). O texto está dividido em cinco seções, incluindo a presente introdução e as considerações finais. A seção seguinte a esta introdução apresenta uma breve revisão dos principais conceitos mobilizados (acumulação primitiva, acumulação por espoliação, desenvolvimento desigual, o papel do Estado no processo de desenvolvimento regional). Em seguida, analisar-se-ão dados socioeconômicos do Paraná e dos municípios que formam o território Cantuquiriguaçu. $\mathrm{Na}$ quarta seção serão considerados elementos à luz da hipótese da acumulação por espoliação. Por fim, apresentam-se as considerações finais.

\section{DESENVOLVIMENTO DESIGUAL, ACUMULAÇÃO POR DESPOSSESSÃO E O ESTADO CONTEMPORÂNEO}

Para uma análise informada pela hipótese do desenvolvimento desigual, com base, principalmente, na condição socioeconômica de um território, parte-se das diferenças existentes quanto a renda e riqueza. Neste sentido, cabe examinar os diversos conceitos relacionados à acumulação do capital. Aqui, consideram-se, sobretudo, os conceitos de acumulação primitiva (MARX, 2013) e acumulação por espoliação (HARVEY, 2004) para a compreensão do avanço do capitalismo e os efeitos dele decorrentes. Quanto ao desenvolvimento desigual, as abordagens teóricas a que se faz referência têm origem nas contribuições da geografia crítica. Como, com o avanço da globalização tem havido questionamentos a respeito da centralidade do Estado-Nação, cabe, brevemente, rever que importância lhe resta, sobretudo, no que tange a sua contribuição para a promoção do desenvolvimento regional.

Pode-se ver o desenvolvimento e o avanço do capitalismo como um processo indissociável da "acumulação primitiva". Esta nada mais é que "o processo histórico de separação entre o produtor e o meio de produção” (MARX, 2013, p. 786). Ou seja, a partir do momento em que os produtores são separados dos meios de produção, eles passam a ser trabalhadores, que necessitam vender a sua mercadoria, no caso, a força de trabalho, para adquirir os recursos necessários a sua subsistência. A apropriação dos recursos produtivos permite ao capitalista 
acumular cada vez mais capital, graças à obtenção do excedente gerado pelo trabalhador, a mais-valia. O surgimento da força de trabalho como mercadoria tem origem no deslocamento das populações rurais em direção aos centros urbanos. Tal situação aprofunda a dificuldade do trabalhador em produzir os meios para a sua subsistência, exigindo sua inserção no mercado de trabalho. Como consequência, o trabalhador passa a demandar uma quantidade maior de outros produtos que já não consegue produzir, pois não possui mais os meios de produção.

Como o avanço do capitalismo não é uniforme no tempo e no espaço, pode-se pressupor que o processo de acumulação primitiva permanece até os dias atuais. Evidentemente, as condições presentes são diferentes e o processo não se repete como nos séculos XVIII e XIX. Entretanto, é possível identificar situações semelhantes de expropriação de terras em regiões mais afastadas e que ainda não estão devidamente inseridas no modo de produção capitalista. De fato, situações decorrentes da separação entre o trabalhador e os meios de produção se repetem ao longo da história. Para Harvey:

"Estão aí a mercadificação e a privatização da terra e a expulsão violenta de populações camponesas; a conversão de várias formas de direitos de propriedade (comum, coletiva, do Estado etc.) em direitos exclusivos de propriedade privada; a supressão dos direitos dos camponeses às terras comuns [partilhadas]; a mercadificação da força de trabalho e a supressão de formas alternativas (autóctones) de produção e de consumo; processos coloniais, neocoloniais e imperiais de apropriação de ativos (inclusive de recursos naturais); a monetização da troca e a taxação, particularmente da terra; o comércio de escravos; e a usura, a dívida nacional e em última análise o sistema de crédito como meios radicais de acumulação primitiva. O Estado, com seu monopólio da violência e suas definições da legalidade, tem papel crucial no apoio e na promoção desses processos [...]. O papel desenvolvimentista do Estado começou há muito tempo, e vem mantendo as lógicas territorial e capitalista do poder sempre interligadas, ainda que não necessariamente convergentes" (HARVEY, 2004, p. 121).

Assim, casos de expulsão violenta de camponeses, privatizações, entre outros, constituem práticas de acumulação primitiva semelhantes as ocorridas na Europa antes da industrialização. Tais situações ocorrem com a anuência e, até mesmo, com o auxílio do Estado. Diante do caráter de continuidade dessas usurpações, este processo pode ser designado de acumulação por espoliação ou acumulação por despossessão (HARVEY, 2004, p. 121).

Com relação ao entendimento sobre o desenvolvimento desigual, Smith considera que "a desigualdade social estampada na paisagem geográfica e é simultaneamente, a exploração daquela desigualdade geográfica para certos 
fins sociais determinados" (SMITH, 1988, p. 221). Sobre as teses a respeito do desenvolvimento desigual, o primeiro esboço teórico é atribuído a Lênin (THEIS, 2009, p. 243). Esta concepção é desenvolvida e aprimorada com Trotsky, sendo então denominada de desenvolvimento desigual e combinado (THEIS, 2009, p. 243-244). Smith (1988) vai rediscutir o desenvolvimento desigual ao atribuir maior importância ao espaço geográfico. Ao trabalhar com a ótica marxista, Smith caracteriza que o desenvolvimento desigual é inerente ao sistema capitalista e que é fruto do vaivém do capital. E o próprio avanço do capitalismo ocasionaria um desenvolvimento desigual no espaço. Afinal, o capital se desloca em busca de maiores lucros, o que pode provocar situações de expansão e retração das atividades econômicas no espaço. Smith trabalha ainda com a perspectiva de que a divisão do trabalho é decorrente da diferenciação territorial do trabalho (SMITH, 1988).

O desenvolvimento geográfico desigual, conceito trabalhado por Harvey, consiste na análise geográfica acerca da desigualdade socioeconômica entre regiões e países, sendo que esta desigualdade é resultado do modo de produção capitalista (THEIS; BUTZKE, 2010, p. 125). Significa dizer que a própria dinâmica do capitalismo transforma os espaços, ocasionando desigualdades territoriais. Acerca da teoria do desenvolvimento geográfico desigual, Harvey considera dois elementos relacionados: produção de escalas espaciais e produção das diferenças geográficas (SANTOS JÚNIOR, 2014, p. 11). Harvey ressalta ainda que o desenvolvimento geográfico desigual é condição para a valorização do capital e resultado das diferenças existentes entre os espaços mais e menos desenvolvidos (THEIS; BUTZKE, 2010, p. 127). Assim, a busca de maiores lucros pelo capital provoca distorções ainda maiores, promovendo a elevação das desigualdades regionais.

Diante da intensificação do processo de globalização ocorrido em todo o planeta, há indícios que apontam para uma suposta redução da capacidade de intervenção dos Estados em suas economias. Obviamente, os efeitos da globalização são heterogêneos entre países e regiões. Contudo, são remotas as áreas nas quais a globalização ainda não produziu efeitos, mesmo que indiretamente. Por exemplo, a globalização provocou grandes alterações no comércio internacional. Com a adoção de medidas neoliberais pelos governos nacionais, aumentaram as dificuldades dos países menos desenvolvidos (PORTOGONÇALVES, 2006). A redução da capacidade de ação do Estado diminuiu suas condições quanto a formulação de políticas públicas, geralmente, voltadas à redução das desigualdades socioeconômicas (internas e externas). Todavia, parte das dificuldades com que os Estados têm tido que lidar decorrem, ironicamente, 
da adoção de medidas que intensificam o processo de globalização favorecendo, explicita ou implicitamente, bancos e grandes empresas, inclusive, sediadas no exterior.

Contudo, desconsiderar a importância do Estado no sentido de promover ações que mitiguem os efeitos nefastos da globalização e do neoliberalismo seria um grande equívoco. Afinal, não há evidências de que a intensificação da globalização, per se, promoverá o desenvolvimento das regiões e países menos desenvolvidos. Também não parece verossímil que experiências localistas em geral, baseadas em estimativas exageradas das capacidades endógenas das regiões, poderão conduzir à redução expressiva das desigualdades socioeconômicas regionais. Não obstante, o agente responsável pelas políticas governamentais, em especial, a política econômica que possam produzir resultados satisfatórios para a população é o Estado. Evidentemente, há diferenças quanto ao grau de intervenção (Estados-Nação e subnacionais). Porém, diante de um cenário de aumento das desigualdades entre países e regiões nos últimos anos, reorientar a ação do Estado é necessário.

\section{DESENVOLVIMENTO NO PARANÁ E O TERRITÓRIO CANTUQUIRIGUAÇU}

O Paraná detém o quarto maior Produto Interno Bruto (PIB) estadual do país. Está localizado na região Sul, possuindo 399 municípios e uma área de $199.880 \mathrm{~km}^{2}$ (IPARDES). Em 2010 detinha uma população de 10.444 .526 habitantes (IPARDES, 2016), sendo Curitiba a sua capital. O Estado tem tido um desempenho satisfatório quanto ao crescimento econômico nos últimos anos. No período compreendido entre 2002 e 2014, apenas em três anos houve retração econômica. Na tabela 1 têm-se os dados referentes ao PIB do Paraná, ao PIB per capita e a variação anual do PIB nesse período.

A tabela 1 indica claramente o avanço gradativo no PIB percapita paranaense no período observado. Este aumento de renda per capita acompanhou o PIB per capita brasileiro, porém, os números paranaenses sempre foram superiores à média nacional neste período. Com relação a variação real do PIB paranaense, o qual indica o crescimento econômico do Estado, o Paraná recuou em três anos: $2005(-0,01 \%), 2009(-1,32 \%)$ e 2012 (-0,1\%). Além disso, é importante destacar a elevação da participação do PIB paranaense na composição do PIB nacional. O Paraná tem elevado esta participação nos últimos anos, saindo de 5,80\% para 6,30 do PIB brasileiro (IPARDES, 2016). 


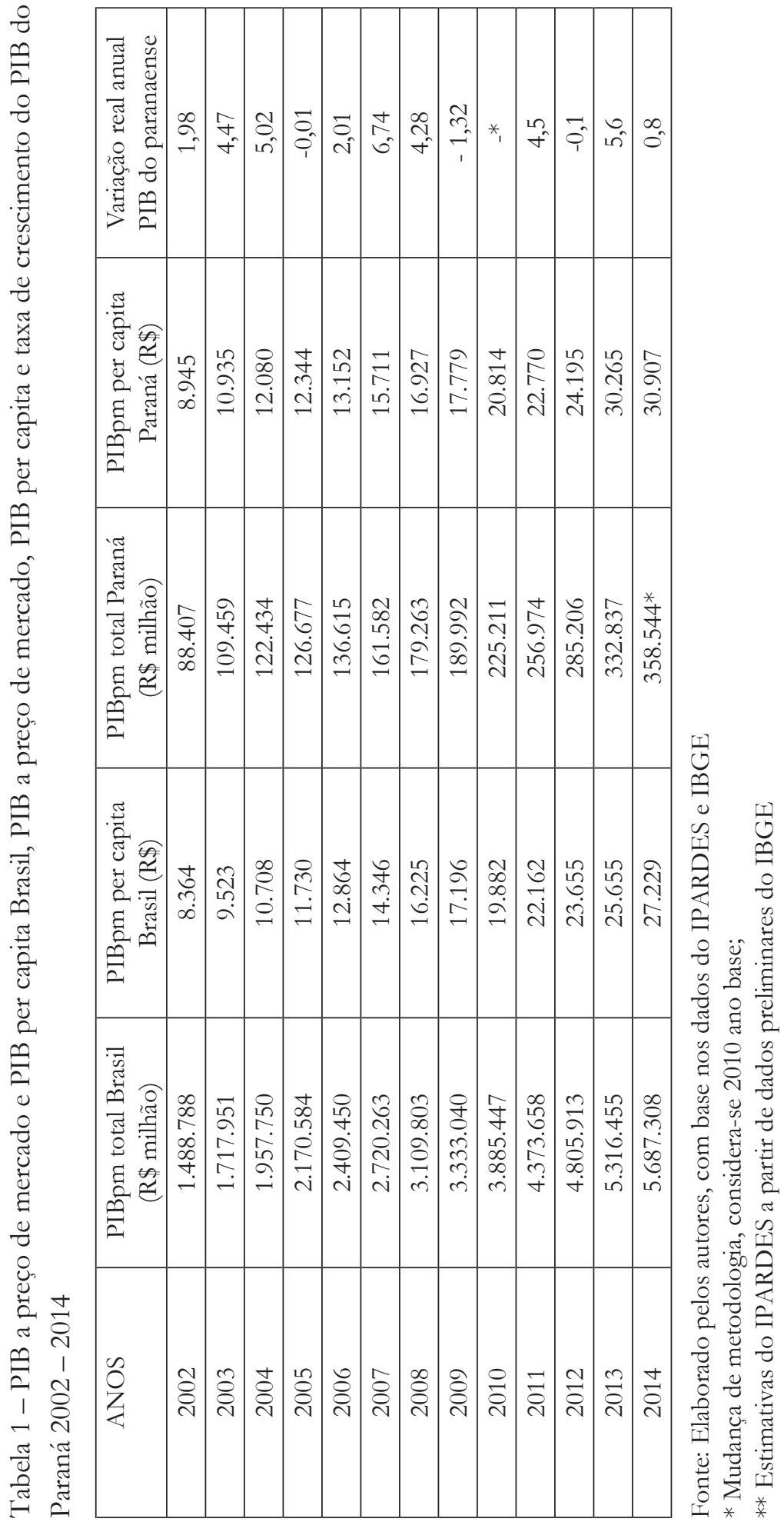


O Território Cantuquiriguaçu abrange uma área de $13.986,40 \mathrm{~km}^{2}$, o que equivale a, praticamente, 7\% do território paranaense (TERRITÓRIOS DA CIDADANIA, 2015). A sede do Território Cantuquiriguaçu está situada no município de Laranjeiras do Sul, o qual está distante $360 \mathrm{~km}$ da capital do Estado, sendo que Laranjeiras do Sul já foi capital do extinto Território Federal do Iguaçu (1943-1946). A denominação Cantuquiriguaçu é decorrente de que parte de sua área geográfica é cercada por três rios: ao norte com o rio Piquiri, a Oeste com o rio Cantu e ao sul com o rio Iguaçu. O território possuí vinte municípios: Campo Bonito, Candói, Cantagalo, Catanduvas, Diamante do Sul, Espigão Alto do Iguaçu, Foz do Jordão, Guaraniaçu, Goioxim, Ibema, Laranjeiras do Sul, Marquinho, Nova Laranjeiras, Pinhão, Porto Barreiro, Quedas do Iguaçu, Reserva do Iguaçu, Rio Bonito do Iguaçu, Três Barras do Paraná e Virmond. Em 2010, a população total do território alcançava 232.546 habitantes, dos quais $46 \%$ vivem na área rural (TERRITÓRIOS DA CIDADANIA, 2015). A figura 1, a seguir, aponta a localização dos municípios e do Território Cantuquiriguaçu no Estado paranaense.

Figura 1- Estado do Paraná, Território Cantuquiriguaçu e seus municípios

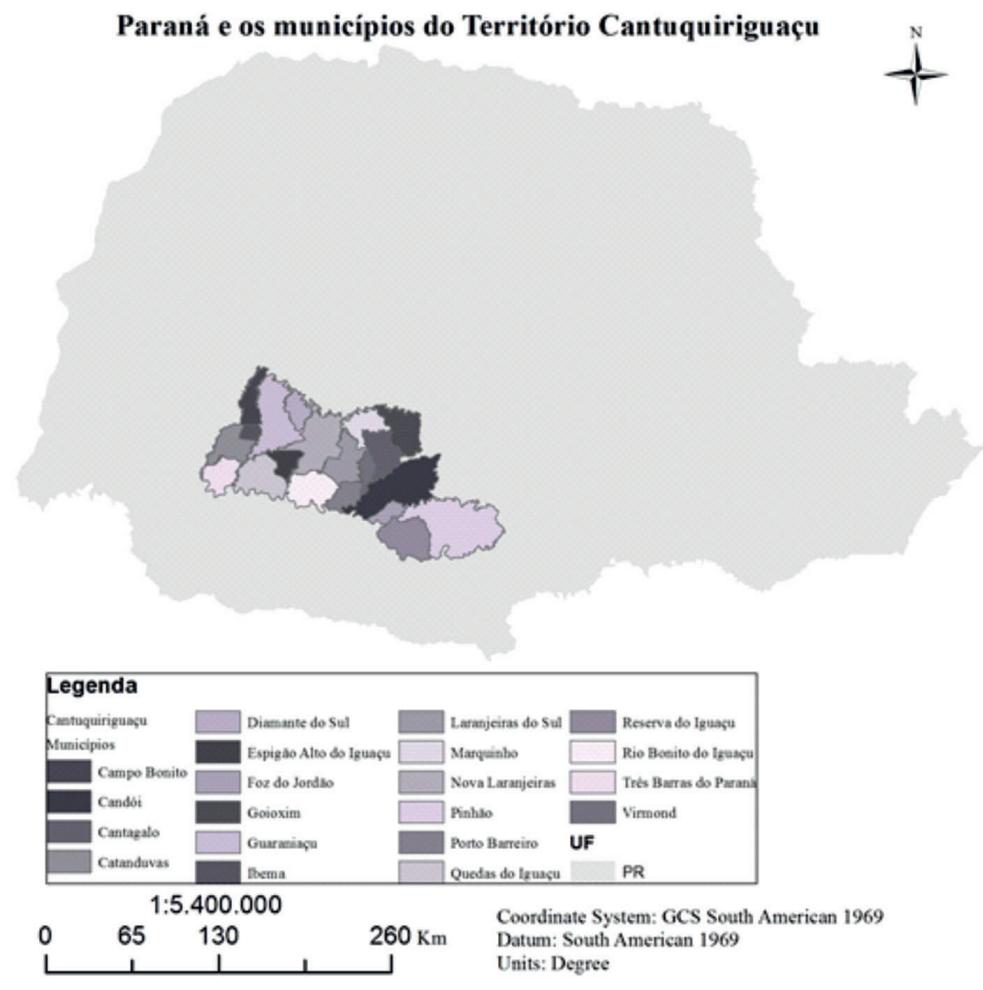

Fonte: Elaboração própria.

Novos Cadernos NAEA • v. 20 n. $2 \cdot$ p. 9-26 • maio-ago 2017 
A tabela 2 apresenta o PIB dos municípios pertencentes do Território Cantuquiriguaçu entre 2010 e 2013. Na maioria dos municípios, o PIB cresceu ano a ano, apesar de algumas exceções. Os cinco maiores PIB's em 2013 são: Quedas do Iguaçu, Pinhão, Laranjeiras do Sul, Candói e Guaraniaçu. Se comparado ao ano de 2010, houve uma inversão apenas entre os dois primeiros colocados, pois Pinhão detinha o maior PIB seguido de Quedas do Iguaçu. Por outro lado, Marquinho, Porto Barreiro, Virmond, Espigão Alto do Iguaçu e Diamante do Sul são os cinco menores PIB's da região. Quando se compara com o ano de 2010, houve uma alteração, pois, Foz do Jordão que era o terceiro menor PIB, em 2013 deixa de fazer parte dos cinco menores, sendo substituído por Virmond. Ainda que seja interessante identificar os motivos pelos quais os municípios anteriormente descritos crescem mais ou menos, esta análise não é objeto deste estudo, sendo um problema para eventual pesquisa no futuro.

Tabela 2 - PIB municipal 2010-2013 (em milhares R\$, preços correntes) e PIB per capita de 2013 (em R\$), dos municípios pertencentes ao Território Cantuquiriguaçu

\begin{tabular}{lrrrrr}
\hline \multicolumn{1}{c}{ Município } & \multicolumn{1}{c}{2010} & \multicolumn{1}{c}{2011} & \multicolumn{1}{c}{2012} & \multicolumn{1}{c}{2013} & \multicolumn{1}{c}{ PIB per } \\
capita 2013 \\
Campo Bonito & 76.037 & 96.664 & 107.802 & 137.087 & 31.435 \\
Candói & 220.434 & 257.526 & 297.156 & 378.729 & 24.189 \\
Cantagalo & 110.303 & 130.706 & 150.815 & 178.771 & 13.345 \\
Catanduvas & 136.461 & 164.054 & 160.908 & 212.771 & 20.328 \\
Diamante do Sul & 51.252 & 56.732 & 66.351 & 84.880 & 16.251 \\
Espigão Alto do Iguaçu & 50.051 & 58.398 & 64.741 & 84.565 & 18.217 \\
Foz do Jordão & 49.333 & 61.753 & 68.048 & 86.039 & 16.094 \\
Goioxim & 68.177 & 83.746 & 97.154 & 136.931 & 18.041 \\
Guaraniaçu & 176.941 & 208.574 & 214.947 & 258.536 & 17.989 \\
Ibema & 70.239 & 74.953 & 83.716 & 112.942 & 17.910 \\
Laranjeiras do Sul & 293.355 & 342.208 & 384.372 & 493.387 & 15.449 \\
Marquinho & 38.284 & 38.232 & 40.439 & 54.599 & 10.997 \\
Nova Laranjeiras & 86.309 & 92.488 & 103.635 & 134.416 & 11.192 \\
Pinhão & 805.143 & 909.317 & 840.645 & 1.018 .539 & 32.215 \\
Porto Barreiro & 45.275 & 52.315 & 52.722 & 68.653 & 18.861 \\
Quedas do Iguaçu & 784.152 & 837.759 & 915.242 & 1.090 .420 & 33.662 \\
Reserva do Iguaçu & 66.996 & 81.902 & 102.988 & 128.980 & 16.757 \\
Rio Bonito do Iguaçu & 119.225 & 136.953 & 145.150 & 198.519 & 14.679 \\
Três Barras do Paraná & 160.085 & 186.964 & 191.423 & 252.895 & 20.736 \\
Virmond & 53.466 & 134.570 & 62.497 & 84.360 & 20.702 \\
\hline Fonte: Elabor & & & & &
\end{tabular}

Fonte: Elaborado pelos autores, conforme dados do IPARDES

Nota: Considerando PIB e PIB per capita em preços correntes 
Considerando os valores correntes, os municípios que apresentaram maior crescimento no período foram Goioxim, Reserva do Iguaçu e Campo Bonito. Por outro lado, os menores crescimentos foram registrados nos municípios de Pinhão, Quedas do Iguaçu e Marquinho. Curiosamente, Quedas e Pinhão são os dois maiores PIB's municipais do território, enquanto Marquinho apresenta o menor PIB. Com relação ao PIB percapita, ao comparar-se os dados dos municípios da região com o Estado (ano 2013), verifica-se que apenas três apresentaram resultado superior à média paranaense $(\mathrm{R} \$ 30.265)$ : Quedas do Iguaçu, Pinhão e Rio Bonito do Iguaçu. Porém, quatro municípios têm renda per capita abaixo de 50\% da renda per capita estadual: Marquinho, Nova Laranjeiras, Cantagalo e Rio Bonito do Iguaçu. Os resultados indicam, pois, que as políticas públicas voltadas ao incremento da atividade econômica dos municípios do Território não produziram efeitos mais expressivos no período considerado.

Com relação ao Índice de Desenvolvimento Humano Municipal (IDHM ), o Paraná apresenta resultado acima da média brasileira, sendo que em 2010, o Estado passou para a quinta posição no ranking das unidades da federação. Porém, ainda é considerado um Estado em desenvolvimento (IDH 0,749), conforme a classificação utilizada pelo Programa das Nações Unidas para o Desenvolvimento (PNUD).

Tabela 3 - IDHM de 1991, 2000 e 2010, ranking estadual dos municípios (2010) e Índice de Gini dos municípios do Território Cantuquiriguaçu (2010)

\begin{tabular}{|l|c|c|c|c|c|}
\hline Município & 1991 & 2000 & 2010 & $\begin{array}{c}\text { Ranking } \\
\text { Paraná 2010 }\end{array}$ & $\begin{array}{c}\text { Índice Gini } \\
(2010)\end{array}$ \\
\hline Campo Bonito & 0,371 & 0,512 & 0,681 & $295^{\circ}$ & 0,48 \\
\hline Candói & 0,309 & 0,509 & 0,635 & $378^{\circ}$ & 0,54 \\
\hline Cantagalo & 0,334 & 0,516 & 0,635 & $378^{\circ}$ & 0,51 \\
\hline Catanduvas & 0,421 & 0,569 & 0,678 & $308^{\circ}$ & 0,53 \\
\hline Diamante do Sul & 0,332 & 0,488 & 0,608 & $393^{\circ}$ & 0,45 \\
\hline $\begin{array}{l}\text { Espigão Alto do } \\
\text { Iguaçu }\end{array}$ & 0,319 & 0,529 & 0,636 & $376^{\circ}$ & 0,57 \\
\hline Foz do Jordão & 0,363 & 0,516 & 0,645 & $363^{\circ}$ & 0,54 \\
\hline Goioxim & 0,227 & 0,446 & 0,641 & $368^{\circ}$ & 0,49 \\
\hline Guaraniaçu & 0,398 & 0,575 & 0,677 & $310^{\circ}$ & 0,54 \\
\hline Ibema & 0,374 & 0,531 & 0,685 & $288^{\circ}$ & 0,44 \\
\hline Laranjeiras do Sul & 0,464 & 0,598 & 0,706 & $199^{\circ}$ & 0,54 \\
\hline Marquinho & 0,228 & 0,433 & 0,614 & $389^{\circ}$ & 0,50 \\
\hline
\end{tabular}

2 O IDHM considera três elementos fundamentais para sua apuração: vida longa e saudável, acesso ao conhecimento e padrão de vida (ATLAS BRASIL, 2016). 


\begin{tabular}{|l|c|c|c|c|c|}
\hline Nova Laranjeiras & 0,298 & 0,528 & 0,642 & $367^{\circ}$ & 0,56 \\
\hline Pinhão & 0,360 & 0,526 & 0,654 & $354^{\circ}$ & 0,53 \\
\hline Porto Barreiro & 0,327 & 0,544 & 0,688 & $272^{\circ}$ & 0,52 \\
\hline Quedas do Iguaçu & 0,420 & 0,593 & 0,681 & $295^{\circ}$ & 0,58 \\
\hline Reserva do Iguaçu & 0,490 & 0,554 & 0,648 & $362^{\circ}$ & 0,57 \\
\hline $\begin{array}{l}\text { Rio Bonito do } \\
\text { Iguaçu }\end{array}$ & 0,319 & 0,466 & 0,629 & $383^{\circ}$ & 0,50 \\
\hline $\begin{array}{l}\text { Três Barras do } \\
\text { Paraná }\end{array}$ & 0,402 & 0,568 & 0,681 & $295^{\circ}$ & 0,50 \\
\hline Virmond & 0,380 & 0,572 & 0,722 & $115^{\circ}$ & 0,53 \\
\hline
\end{tabular}

Fonte: Elaborado pelo autor, conforme dados disponǵveis no Atlas Brasil (2013)

Ao analisar o IDHM e o Índice de Gini dos municípios do Território Cantuquiriguaçu, a partir da tabela 3, obtém-se que:

- Todos os municípios da região apresentam IDHM inferior à média estadual $(0,749)$;

- Apenas Laranjeiras do Sul e Virmond estão entre os duzentos municípios considerados mais desenvolvidos;

- Metade dos 20 municípios do território estão entre os 10\% considerados menos desenvolvidos;

- Apesar de os municípios apresentarem evolução no IDHM, no período de 1991-2010, o resultado é insuficiente para classificar qualquer município como desenvolvido.

- Conforme o Índice de Gini, onze municípios do território apresentam concentração de renda igual ou maior que a média paranaense $(0,53)$.

Diante do exposto, se infere que os dados apresentados reforçam a ideia do baixo desenvolvimento da região que compreende o território Cantuquiriguaçu. Apesar da melhoria em alguns indicadores, como o IDHM, a região continua enfrentando dificuldades e não consegue acompanhar o desenvolvimento socioeconômico paranaense. Alguns fatores podem contribuir para uma explicação do baixo desenvolvimento da região, tais como: falta de dinamismo econômico, políticas de desenvolvimento regional insuficientes, baixo investimento em saúde e educação, entre outros. Entretanto, cabe averiguar quais as ações que o Estado paranaense tem adotado nos últimos anos frente a este desenvolvimento desigual.

3 Índice de Gini: mede o grau de desigualdade segundo a renda per capita. Seu valor varia entre 0 (renda desconcentrada) e 1 (renda concentrada), ou seja, quanto maior o índice, maior a concentração de renda (ATLAS BRASIL, 2016). 


\section{UMA ANÁLISE: DESENVOLVIMENTO DESIGUAL NO PARANÁ E O TERRITÓRIO CANTUQUIRIGUAÇU}

Considerando que parte dos municípios do Território Cantuquiriguaçu foram criados no final do século $\mathrm{XX}^{4}$, há, por um lado, uma dificuldade substancial a respeito da definição de estratégias de desenvolvimento municipal. Por outro, há uma injeção de recursos maior visando constituir a infraestrutura necessária ao funcionamento desses municípios. Porém, ainda que o período observado não seja tão longo, é possível comparar os indicadores municipais com os do Estado do Paraná. Apesar de a Constituição Federal de 1988 conferir maiores atribuições aos municípios, a capacidade de arrecadação municipal é limitada, pois boa parte da arrecadação tributária brasileira é transferida à União. Tal situação, aliada a capacidade reduzida de formulação de políticas públicas (ainda mais em municípios novos e menores), dificulta a adoção de práticas que promovam melhorias na qualidade de vida da população. Daí a necessidade de uma participação ativa do governo estadual (e federal) na adoção de políticas públicas que promovam o desenvolvimento regional.

Ainda que uma política pública específica não seja objeto deste trabalho, é possível constatar que as ações governamentais a partir de 1994 não conduziram à redução das desigualdades intra-regionais. O período de observação é apropriado dados os seguintes fatores: período de criação dos municípios, estabilidade monetária no país (Plano Real) e início de mandato do governo Jaime Lerner (governador em dois períodos: 1995-1998 e 1999-2002). Este, por sua vez, foi sucedido por Roberto Requião (2003-2006 e 2007-2010). E este antecedeu o governo Beto Richa (2010-2014 e 2015-2018). Há de se mencionar que Roberto Requião também foi governador no período anterior a esta análise (1991-1994). Convém ressaltar ainda que, neste período, o discurso neoliberal encontra um cenário amplamente favorável no Brasil, do que é prova a abertura comercial do começo daquela década.

O governo Lerner ficou marcado pela implementação de medidas que condiziam com o receituário neoliberal. Alguns exemplos podem ser apontados para comprová-la. Em 1997 deu-se início ao Programa de Concessões de Rodovias - atualmente mais de $2.500 \mathrm{~km}$ da malha rodoviária estadual estão concedidos à iniciativa privada (DEPARTAMENTO DE ESTRADAS DE RODAGEM/PR, 2015). Outra privatização de grande impacto foi a venda do Banco do Estado do Paraná - BANESTADO para o Grupo Itaú, em 2000,

\footnotetext{
4 No último quarto de século, foram criados quinze municípios do território, sendo onze na década de 1990 (Ferreira, 1990).
} 
além da tentativa de privatização da Companhia Paranaense de Energia Elétrica COPEL, também no início dos anos 2000. Não obstante, seu governo participou da guerra fiscal travada entre os Estados brasileiros na época visando atrair montadoras de automóveis. Atingiu seu intento ao garantir a vinda da francesa Renault para o município de São José dos Pinhais, Região Metropolitana de Curitiba. Posteriormente, Chrysler e Audi/Volkswagen também se instalaram na região (OLIVEIRA, 2003, p. 133).

O governo Requião representou uma tentativa de conter a onda de privatizações e as práticas do Estado mínimo. Entretanto, em virtude de várias derrotas no campo jurídico, ele não conseguiu reduzir ou acabar com os pedágios (mote de sua campanha eleitoral). Mesmo assim, algumas ações de incentivos às pequenas empresas e aos produtores rurais se diferenciaram em relação ao governo anterior. Outra iniciativa de repercussão foi a ameaça de interrupção dos benefícios à montadora Renault. Medidas adotadas em relação à COPEL e a Companhia de Saneamento do Paraná - SANEPAR indicam que este governo se contrapôs, ideologicamente, ao governo Lerner. De fato, o governo Requião se notabilizaria por ações que visavam um wefare-state, contrapondo-se à política neoliberal adotada anteriormente (RESENDE, 2007, p. 118; 120).

Guardadas as devidas proporções, o governo Beto Richa caminha para uma retomada da política implementada pelo governo Lerner. Parte do grupo político de Lerner assumiria cargos de grande importância no primeiro governo de Beto Richa. O atual governador promoveu nova política de incentivos à Renault, além de tentar prorrogar os contratos de concessão de rodovias. A conduta adotada pelo governo e pela polícia militar (sob comando do governador) do Paraná durante a greve dos professores também indica uma mudança nas relações com o funcionalismo público, se comparada ao governo anterior. Recentemente, o governo aprovou na Assembleia Legislativa do Paraná, numa primeira discussão, o PL 435/2016, o qual prevê, entre outros interesses, a venda de ações das empresas COPEL e SANEPAR (ASSEMBLEIA LEGISLATIVA DO PARANÁ, 2016).

Com isso, as experiências realizadas pelos governos paranaenses nos últimos anos (ressalvado do governo Roberto Requião) indicam a utilização do aparelho estatal para o benefício de grupos econômicos, caracterizando o processo de acumulação por espoliação. Não foi possível identificar políticas públicas específicas voltadas ao desenvolvimento das regiões menos desenvolvidas. Pelo contrário, o incentivo à instalação de montadoras na Região Metropolitana de Curitiba acentuou as discrepâncias existentes entre as regiões do Estado. Em que pese não serem as disparidades exclusivas do território do Paraná, a lógica 
de mercado, apoiada pelo governo do Estado, produziu desigualdades ainda maiores (IPARDES, 2006).

Ao analisarmos os dados e informações obtidas no contexto do Território Cantuquiriguaçu, pode-se observar de que forma esta região foi afetada pelas ações do governo estadual anteriormente descritas. Assim, podemos constatar as seguintes consequências:

_ diante do programa de concessão de rodovias: foram instaladas duas praças de pedágio nos ${ }_{5}$ municípios de Candói e Ląranjeiras do Sul;

_ concessão de duas usinas hidrelétricas da região à iniciativa privada: Usina de Salto Osório e Usina de Salto Santiago ;

_ privatização do BANESTADO: na época era um dos principais bancos públicos do Paraná, com cerca de 346 agências espalhadas pelo Estado, sendo o líder estadual no setor;

_ o alto investimento efetuado visando a atração das montadoras de automóveis para a Região Metropolitana de Curitiba em detrimento de investimentos em regiões mais deprimidas do Estado.

As práticas descritas anteriormente corroboram com a ideia de Harvey no que tange a acumulação por espoliação. A concessão de rodovias, construídas com recursos públicos, à iniciativa privada além de encarecer o deslocamento de pessoas e produtos, prejudica a economia de municípios próximos as praças de pedágios. O deslocamento de pessoas das áreas que seriam alagadas para a construção das usinas hidrelétricas, sem contar ainda a alteração na terra cultivável disponível e alterações na fauna e na flora, afetam profundamente pessoas que habitam nestas partes do território. Apesar da existência de outros bancos públicos, é inegável que boa parte dos clientes mantiveram suas contas numa instituição financeira privada. Não obstante, o investimento em regiões mais dinâmicas economicamente reduz, evidentemente, o volume de recursos que poderiam ser direcionados a outras áreas.

A realidade vivida pelo Território Cantuquiriguaçu destoa dos números apresentados pela economia paranaense: renda per capita estadual bem acima da região, elevação na participação do PIB estadual frente ao PIB nacional e investimentos expressivos na economia em regiões mais desenvolvidas representam, de certa forma, um ultraje a regiões menos desenvolvidas. E mais, as práticas retratadas previamente propiciam um desenvolvimento ainda mais desigual. Apesar de algumas melhorias, como no IDHM e Índice de Gini por

\footnotetext{
Usina Salto Osório: situada entre os municípios de São Jorge d'Oeste e Quedas do Iguaçu;

Usina Salto Santiago: localizada no município de Saudade do Iguaçu, contudo, para a viabilização de sua construção, várias áreas dos municípios pertencentes ao Território Cantuquiriguaçu foram "alagadas", em especial, áreas do município de Rio Bonito do Iguaçu.
} 
exemplo, não há nada que aponta efetivamente um desenvolvimento maior no Território Cantuquiriguaçu.

\section{CONSIDERAÇÕES FINAIS}

Nos anos 1990, o discurso e a prática em relação à forma de intervenção estatal foram marcados pela redução da participação do Estado na economia. As políticas econômicas do governo federal nessa década caminharam neste sentido, diminuindo consideravelmente a capacidade do Estado de atuar e intervir. No âmbito das políticas estaduais, é preciso levar em conta as políticas governamentais que visavam o desenvolvimento de regiões menos desenvolvidas. Neste sentido, cabe atentar para as políticas públicas de desenvolvimento regional adotadas pelos governos Lerner, Requião e Richa. As observações iniciais, presentes neste texto, indicam a reprodução no Paraná de práticas de redução da ação estatal. A defesa da redução do papel do Estado na economia, intensificada no Brasil a partir do início dos anos 1990, encontrou um campo fértil no governo Lerner. As políticas adotadas no governo Lerner e Beto Richa condizem com práticas que favorecem a acumulação por espoliação, de acordo com Harvey.

Assim, as ações estatais adotadas pelos governos estaduais do Paraná, salvo ao do governo Requião, foram condizentes com o projeto neoliberal. Mesmo que eventuais medidas visassem promover o desenvolvimento de regiões econômica e socialmente mais deprimidas, estas revelaram-se infrutíferas. Apesar de as características ideológicas e as políticas públicas adotadas terem sido diferentes em cada um dos governos analisados, o impacto sobre o desenvolvimento regional paranaense não surtiu os efeitos esperados, entre os quais, a redução inter-regional das desigualdades socioeconômicas. As evidências para isso se encontram nos dados socioeconômicos do território Cantuquiriguaçu. O baixo grau de desenvolvimento socioeconômico indica o insucesso das políticas governamentais direcionadas ao desenvolvimento do Território. É inegável que a região apresenta indicadores socioeconômicos muito inferiores as médias paranaenses, reafirmando a ideia de que as ações que visavam seu desenvolvimento ficaram aquém dos resultados esperados.

Como visto, o desenvolvimento do Território Cantuquiriguaçu não acompanha o desenvolvimento do Estado do Paraná. As políticas governamentais parecem promover a expansão de economias e regiões dinâmicas em prejuízo de regiões deprimidas. O conjunto das ações anteriormente expostas caracteriza um processo de acumulação por espoliação. E este possibilita, infelizmente, um desenvolvimento ainda mais desigual. Entretanto, é provável que este 
desenvolvimento desigual seja realmente o propósito de alguns governos, visto que este é útil ao processo de acumulação do capital.

A importância de se analisar o desenvolvimento regional e suas implicações econômicas, sociais e políticas está em que assim se podem compreender melhor os motivos pelos quais certas regiões se desenvolvem e outras não. Nesta perspectiva, seria oportuno examinar algumas características específicas do Território Cantuquiriguaçu, tais como: ausência de grandes investimentos econômicos, pouco dinamismo de sua economia, redução do contingente populacional e baixo grau de desenvolvimento, entre outros. Além disso, caberia investigar as políticas estaduais específicas de estímulo ao desenvolvimento regional e de redução das desigualdades socioeconômicas. Outra questão que mereceria maior atenção é a das privatizações ocorridas no Paraná e seu impacto sobre o desenvolvimento socioeconômico das microrregiões do Estado. Que este trabalho, limitado a verificar até que ponto o Estado paranaense, através do processo de acumulação por espoliação, contribui para o desenvolvimento desigual, tenha contribuído no debate sobre tão importante tema.

\section{REFERÊNCIAS}

AGÊNCIA DE NOTÍCIAS DO PARANÁ. Richa entrega carta de intenções para atrair novos investimento da Renault. Publicado em 29 de agosto de 2011. Disponível em: <http://www.aen.pr.gov.br/modules/noticias/article. php?storyid=65379> . Acesso em 08 de jul. 2015

ASSEMBLEIA LEGISLATIVA DO PARANÁ. Assembleia aprova cinco projetos com ajustes fiscais do Poder Executivo. 2016. Disponível em: <http://www.alep.pr.gov.br/sala_de_imprensa/noticias/assembleia-aprovacinco-projetos-com-ajustes-fiscais-do-poder-executivo $>$. Acesso em 13 de set. de 2016.

ATLAS BRASIL. Consulta. 2013. Disponível em: < http://atlasbrasil.org. br/2013/consulta/>. Acesso em 30 set. 2013.

ATLAS BRASIL. Ranking. 2013. Disponível em: < http://atlasbrasil.org. br/2013/ranking >. Acesso em 29 set. 2013.

CANTUQUIRIGUAÇU. Sobre a Cantuquiriguaçu. Laranjeiras do Sul, [2013]. Disponível em: <http://cantuquiriguacu.com.br/sobre.php>. Acesso em 11 mai. 2013.

CONDETEC. Território Cantuquiriguaçu: Paraná: diagnóstico socioeconômico. Curitiba, 2004. 
DEPARTAMENTO DE ESTRADAS DE RODAGEM DO PARANA. Rodovias Concessionadas. 2015. Disponível em: <http://www.der.pr.gov.br/ modules/conteudo/conteudo.php?conteudo=271>. Acesso em 10 jul. 2015.

FERREIRA, João Carlos Vicente. O Paraná e seus municípios. Cuiabá: J.C.V. Ferreira, 1999. 520 p.

GOMES, M. V. Governador do Paraná ameaça suspender incentivos das montadoras que demitirem trabalhadores. Disponível em: <http:// economia.uol.com.br/ultnot/2009/02/06/ult4294u2242.jhtm>. Acesso em 08 jul. 2015.

HARVEY, D. O novo imperialismo. São Paulo: Loyola, 2004.

Instituto Brasileiro de Geografia e Estatística. População. Disponível em: <www.ibge.com.br>. Acesso em 12 mai. 2013.

Instituto Paranaense de Desenvolvimento Econômico e Social. Cadernos Municipais. Curitiba, 2012. Disponível em: <www.ipardes.gov.br>. Acesso em 07 jul. 2015.

Instituto Paranaense de Desenvolvimento Econômico e Social. Diagnóstico Socioeconômico do Território Cantuquiriguaçu: $1^{\text {a }}$ Fase caracterização global. Curitiba: IPARDES, 2007.

IPARDES. Produto interno bruto do Paraná e Brasil a preços correntes. Curitiba, [2013]. Disponível em: <http://www.ipardes.pr.gov.br/pdf/indices/ tab_pib_01.pdf> Acesso em: 19 abr. 2013.

IPARDES. Produto interno bruto per capita do Paraná e Brasil. Curitiba, [2012]. Disponível em: < http://www.ipardes.pr.gov.br/pdf/indices/tab_pib_02. pdf> Acesso em: 19 abr. 2013.

IPARDES. Os Vários Paranás: identificação das espacialidades socioeconômicas-institucionais como subsídio a políticas de desenvolvimento regional. Curitiba: IPARDES, 2006. Disponível em: < http:// www.ipardes.gov.br/biblioteca/docs/varios_paranas_espacialidades.pdf $>$. Acesso em 08 de jul. 2015.

IPARDES - Instituto Paranaense de Desenvolvimento Econômico e Social. (2016). Paraná em números. Disponível em: <http://www.ipardes.gov.br/ index.php?pg_conteudo=1\&cod_conteudo=1>. Acesso em 12 de set. de 2016.

MARX, K. O Capital: crítica da economia política. Trad. R. Enderle. São Paulo: Boitempo, 2013. 
OLIVEIRA, V. L. Estado, Empresariado Regional e o Setor Automotivo no Paraná. Revista Paranaense de Desenvolvimento, Curitiba, $\mathrm{n}^{\circ} 105$, jul/ dez 2003. Disponível em: <http://www.ipardes.pr.gov.br/ojs/index.php/ revistaparanaense/article/view/180/153>. Acesso em 10 jul. 2015.

PORTO-GONÇALVES, C. W. A globalização da natureza e a natureza da globalização. Rio de Janeiro: Civilização Brasileira, 2006 (p. 9-58).

PROGRAMA DAS NAÇÕES UNIDAS PARA O DESENVOLVIMENTO. Desenvolvimento Humano e IDH. Brasília, [2012]. Disponível em: < http:/ / www.pnud.org.br/IDH/DH.aspx?indiceAccordion=0>. Acesso em 20 abr. 2013.

RESENDE, D. C. Elementos decisivos na construção da posição e ação política de Roberto Requião de Mello e Silva. 2007, 165 pp. Dissertação (Mestrado em Sociologia) - Universidade Federal do Paraná - UPFR. Disponível em: <http://www.pgsocio.ufpr.br/docs/defesa/dissertacoes/2007/daiane. pdf $>$. Acesso em 10 jul. 2015.

SANTOS JUNIOR, J. R. dos. David Harvey e a Teoria do Desenvolvimento Geográfico Desigual do Capitalismo. Geografia em Questão, Vol. 07, nº2, 2014. Disponível em: <http://e-revista.unioeste.br/index.php/geoemquestao/ article/download/8865/7621>. Acesso em 10 jul. 2015.

SMITH, N. Desenvolvimento desigual: natureza, capital e a produção do espaço. Trad. E. A. Navarro. Rio de Janeiro: Bertrand Brasil, 1988.

TERRITÓRIOS DA CIDADANIA. Cantuquiriguaçu - PR. Brasília, [2013]. Disponível em: <http://www.territoriosdacidadania.gov.br/dotlrn/clubs/ territriosrurais/cantuquiriguaupr/one-community?page_num $=0>$. Acesso em 26 abr. 2013.

THEIS, I. M. Do desenvolvimento desigual e combinado ao desenvolvimento geográfico desigual. Novos Cadernos NAEA, Belém: Universidade Federal do Pará, v. 2, n 2, p. 241-252, dez. 2009. Disponível em: <http://www.periodicos. ufpa.br/index.php/ncn/article/view/324/510>. Acesso em 10 jul. 2015.

THEIS, I. M.; BUTZKE, L. O desenvolvimento geográfico desigual de uma perspectiva latino-americana. In: Simpósio Lutas Sociais na América Latina: imperialismo, nacionalismo e militarismo no século XXI. Londrina. Anais, 14 a 17 de setembro de 2010. p. 122-131. Disponível em: <http://www.uel. br/grupo-pesquisa/gepal/anais_ivsimp/gt8/13_ivotheis\&lucianabtzke.pdf $>$. Acesso em 07 jul. 2015. 